\title{
MEASURES AGAINST WATER POLLUTION IN INDUSTRIES PRODUCING EDIBLE OILS AND FATS
}

\author{
R. FRANCOIS
}

\author{
Honorary General Manager of the Fats and Oil Research Institute, Paris
}

\begin{abstract}
Edible fats and oils are produced by three main industries: oil, margarine and rendering. As margarine manufacture requires only substances that have already undergone refining, the only waste water comes from rinsing the equipment and premises. The oil industry with its different phases of refining uses large quantities of water but could cut its consumption by a more rational organization of the different circuits. Animal fats processing (rendering), treating raw materials which are easily and rapidly decomposable, uses large quantities of water, not only for washing the raw material but also for thorough cleaning of the premises. This industry could reduce pollution through appropriate improvement in the preparation of the raw material and its collection.

In any case, the successful treatment of polluted water lies in the correct application of modern processes for filtration, settling, precipitation, and other and chemical and biological treatments. Through them, the solid particles in suspension are eliminated, the fatty matter carried off is separated and recovered, emulsified matter is precipitated by flocculation, and the discarded water conforms to prevailing regulations on the discharge of waste water into sewers and

streams.
\end{abstract}

In order to decide upon the exact measures to be taken against water pollution in industries producing edible fats and oils, it is first necessary to know the precise causes and nature of the pollution. Then, we shall study methods of eliminating it or reducing it, in general and in specific cases.

These examinations will be undertaken successively for the three classes of industries producing edible fats and oils: oil factories, the raw materials of which are oleaginous seeds and the pulp of certain fruits; margarine factories, which use oils and animal fats; animal fats factories, treating animal fats: land (tallow, lard) and sea.

\section{OIL INDUSTRIES \\ Nature and proportion of the different types of waste water \\ Until recent years, all waste water was disposed of, even if it had been used only for the production of steam or for heat exchange. \\ At the present time, we are obliged to discharge as little waste water as possible, which leads us to consider three types of water:}

(a) Water returned from the heating system of the equipment (non-polluted). 
(b) Water used in condenser and heat compressor cooling (non-polluted).

(c) Residual waters from oil refining and secondary processing (polluted). In this last group we must consider:

(i) The 'degumming' waters which contain most of the impurities found in crude oils either in solution or in emulsion, in particular : oil carried off, fatty acids, phospholipids including lecithin, sterols, tocopherols, saturated and unsaturated hydrocarbon and glycerol.

(ii) Waste waters from the neutralising rinse which contain some oil carried off, soda, soaps and glycerol.

(iii) During the deodorising process the thermo-compressor condensates carry off a certain quantity of impurities remaining in the oil and not removed by degumming which is never thorough. These impurities are components of what we call the 'unsaponifiable' substances, just mentioned above. It should be noted that the hydrocarbons are to be found in the highest proportion whilst the amount of sterols is always under 10 per cent and the tocopherols are only found in traces.

We shall now attempt to estimate the cost of water used in these different ways.

(a) Water returned from the heating system

During extraction by crushing, 150 to $200 \mathrm{~kg}$ of steam per ton of seeds is to be expected depending on the degree of toasting desired, the moisture content of the seeds, and the equipment.

During extraction by solvent, the amount of steam used for heating only is between 120 and $300 \mathrm{~kg}$ per ton of product treated.

During refining, 120 to $200 \mathrm{~kg}$ of steam are used for heating one ton of oil.

Let us take, for example, the crushing of a ton of peanuts. The $425 \mathrm{~kg}$ of oil and $575 \mathrm{~kg}$ of oil-cake obtained after crushing are sent to the extraction ${ }_{z}$ solvent operation. The heating steam schedule will be divided as follows:

$$
\begin{aligned}
& \text { Crushing: } \quad \frac{175 \times 1000}{425}=411 \mathrm{~kg} \text { per ton of oil obtained } \\
& \text { Extraction }: \frac{230 \times 1000}{75}=3000 \mathrm{~kg} \text { per ton of oil obtained } \\
& \text { Refining: } \\
& \text { Total: }
\end{aligned}
$$

This makes $368000 \mathrm{~kg}$ for 100 tons of oil, or $3.68 \mathrm{~kg}$ per $\mathrm{kg}$ of oil.

This first type of water is usually returned to the boiler or used (fully or in part) as clean water for refining the oil.

(b) Water from condensers and heat compressors in the successive operations of extraction and refining

(i) Extraction of oil from the oil-cake after crushing of the seeds requires about $20 \mathrm{~m}^{3}$ of water per ton of product treated, and if we consider that the 
WATER POLLUTION IN EDIBLE FATS AND OILS INDUSTRIES

cakes undergoing this treatment will contain 12 per cent oil, that represents for $100 \mathrm{t}$ of oil:

$$
\frac{20 \times 1000 \times 100}{120}=16000 \mathrm{~m}^{3}
$$

However, this water is free from impurities and may be recirculated directly after cooling. The temperature rise is generally from $15^{\circ}$ to $25^{\circ} \mathrm{C}$. There is, therefore, no pollution problem here.

(ii) At the refining level the problem is much greater, as the condenser cooling waters are in general collected in the condensates from the heat-compressors which carry off a certain amount of impurities contained in the oil. Quantities may be estimated as follows: $10 \mathrm{~m}^{3}$ of water/t of oil for cooling the oil after the earth separation filter and the final filter after deodorizing (this water is not polluted); $1 \mathrm{~m}^{3}$ of water coming from the heat condensers used for the vacuum in decolorizing and deodorizing operations (it is polluted); $27 \mathrm{~m}^{3}$ of water/t of oil for the barometer shafts in the preceding operation (it is polluted from mixing with the preceding). The total is then $38 \mathrm{~m}^{3} / \mathrm{t}$ of oil or $3800 \mathrm{~m}^{3}$ per $100 \mathrm{t}$, including $1000 \mathrm{~m}^{3}$ of clean water collected separately.

(c) Waste waters from different stages of refining

Supposing that the gums are collected with the neutralising soaps, the only outflow to be run off would be $30 \mathrm{~m}^{3}$ for $100 \mathrm{t}$ of oil, coming from the washing after neutralization.

Furthermore, waste waters coming from the splitting of the soaps and representing $5 \mathrm{~m}^{3} / \mathrm{t}$ of oil must be taken into account.

Composition of the total water used-According to the preceding estimates, we shall have for $100 \mathrm{t}$ of refined oil:

(i) $100 \mathrm{~m}^{3}$ water from the heat compressors containing fatty acids (about $0.06 \%$ ), sterols, tocopherols, terpenes, aliphatic hydrocarbons, and so on that is to say all the aromatic elements of the oil. However, these $100 \mathrm{~m}^{3}$ are often diluted in the $2700 \mathrm{~m}^{3}$ coming from the cooling of the condensers.

(ii) $30 \mathrm{~m}^{3}$ from the washing of the oil, the composition of which varies greatly according to the type of separation used. It contains soaps, gums, oils, soda or other refining agents, and also sterols, tocopherols, etc. The exit temperature is $70-90^{\circ} \mathrm{C}$.

(iii) $5 \mathrm{~m}^{3}$ from the recovery of acid oil containing mineral salts, mineral acids, gums, fatty acids, glycerol and all the breakdown products from the separation.

The total of these is $135 \mathrm{~m}^{3}$ plus $2700 \mathrm{~m}^{3}$ of dilution water givi.ng $3835 \mathrm{~m}^{3}$ for $100 \mathrm{t}$ of oil.

So, from a total of $3835 \mathrm{~m}^{3}$ of waste water per $100 \mathrm{t}$ of oil, only $135 \mathrm{~m}^{3}$ are contaminated, the impurities of which are diluted in about 28 times their volume.

\section{Treatment of the polluted waters}

Water coming from the oil factory is mostly acid and appears as an emulsion of all non-soluble matter, owing to the presence of gums and proteins.

Moreover, if hydrogenation is undertaken, the additional cleaning may also carry off very small quantities of oil and catalyst. 


\section{R. FRANCOIS}

The process of waste water treatment is as follows:

(a) Settling in tank or trays for recovery of the fatty matter carried off.

(b) Clarification to remove the maximum amount of fatty acids and substances in suspension.

(c) Possibly a biological treatment.

Water thus purified may then be discharged to the sewer or stream, after dilution.with clean water if necessary.

(a) Settling

Continuous settlers are well known. The usual types are tanks into which the polluted water flows continuously until a certain level is reached. The flow is slow enough for settling to take place. The fatty matter rises to the top where it is skimmed off (Figure 1).

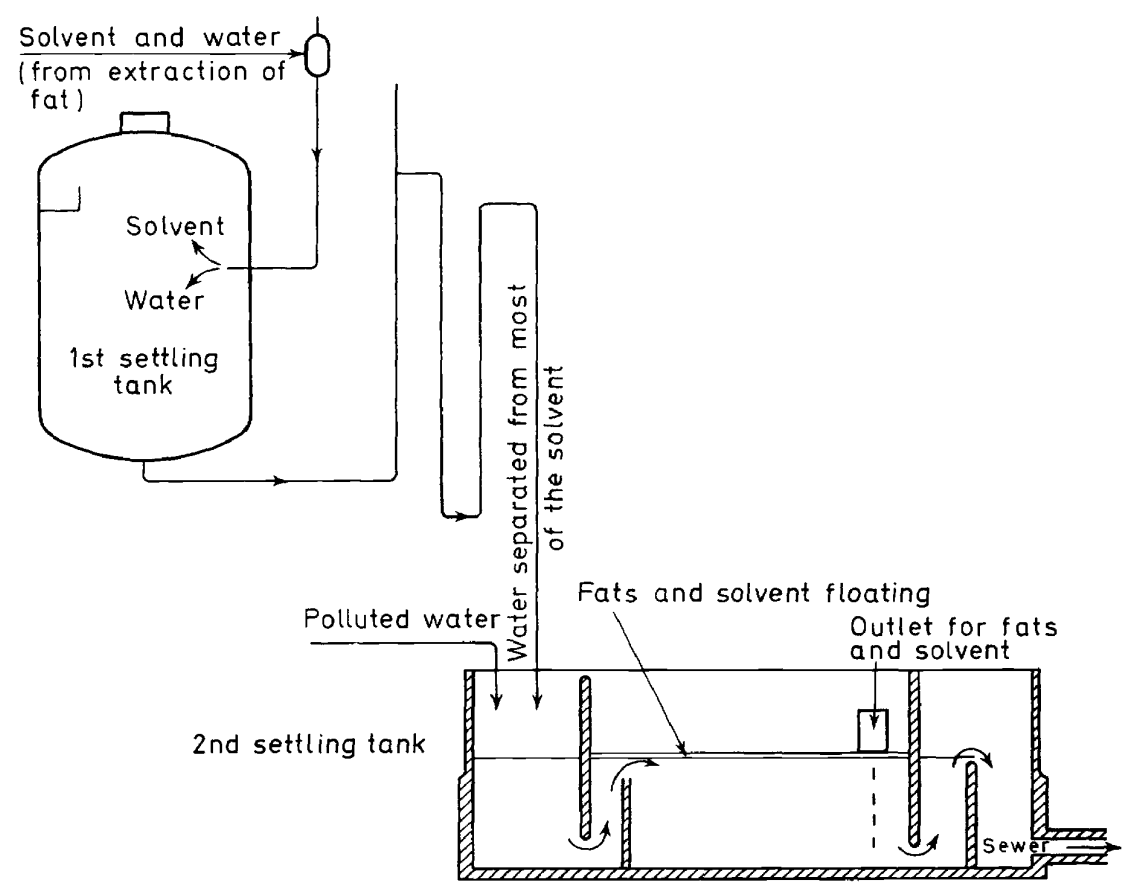

Figure 1. Diagram of waste water settling tank

Two great improvements may be made to the current procedure. One of them consists of the injection of aerated water under pressure into the bottom of the tank. The air bubbles freed when the pressure is released are very fine. As they rise they carry along the particles of fatty matter in suspension. The operation is as follows (Figure 2).

The polluted water is pumped into the tank (tray) A, which is equipped with baffle-plates to calm the flow. The floating fatty matter which would gather and flow off is scraped up into a slope (C), after which being freed from the water which runs back, it falls into an evacuated canal. 
The purified water is partially pumped back (D) to a water pressurizer (E), through an apparatus $(\mathrm{F})$ where it mixes with pressurized air at $6 \mathrm{~kg}$. The pressure in the pressurizer is about $3 \mathrm{~kg}$. The water thus aerated is constantly stirred up by recirculation. It comes out under atmospheric pressure and enters the settling tank partly through the polluted water inlet and partly through the bottom of the settling tank through a diffuser.

The second process called 'slanting plate cells', employs horizontal compartments equipped with a stack of corrugated plates slanting at 45 degrees longitudinally. The settling is carried out along these plates and the water is then run off in the usual manner.

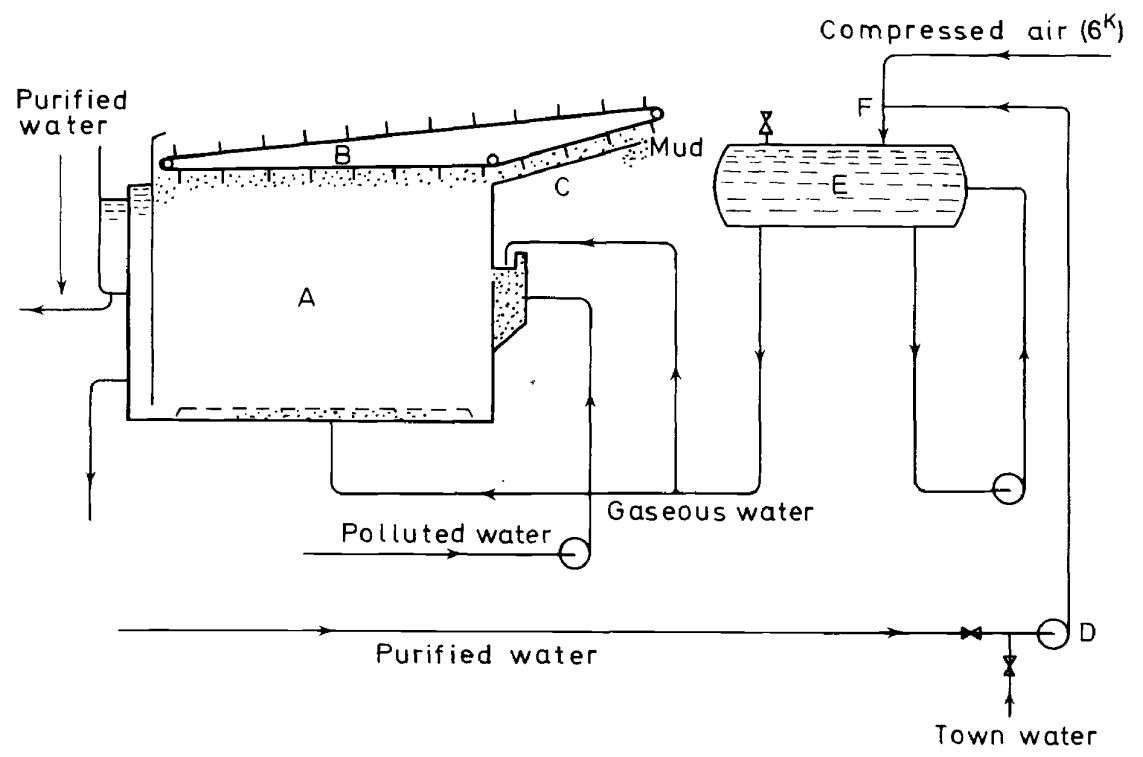

Figure 2. Continuous purification process by flotation.

\section{Clarification}

Among the different techniques investigated in this operation, the best results were obtained by 'flocculation', followed by sedimentation (Figures 3 and 4).

Among the flocculating agents, aluminium sulphate and ferric chloride with added lime, give a satisfactory proportion of deposit.

Lime and caustic soda are also used in a concentration sufficient to give a $\mathrm{pH}$ of 10.5 . All these reagents may be added automatically by following the $\mathrm{pH}$.

The mixture is stirred to enhance coagulation. The flakes formed settle to the bottom of the tank to form a thickening mud.

When the mud content reaches 5 to 20 per cent it is pumped off and conveyed to coke beds for partial drying. It may also be treated by centrifuging or filter-press which is more rapid and more rational. It then contains 60 to 70 per cent of solid matter. Burning is the best means of disposing of it. 


\section{R. FRANCOIS}

The following data give an example of water clarified by this process:

Reduction of BOD to 400 to $500 \mathrm{ppm}$.

Reduction of fatty matter content to less than $85 \mathrm{ppm}$.

Solid matter in suspension : about $100 \mathrm{ppm}$.

The settling tank water contains about $5 \mathrm{ppm}$ of dissolved oxygen.

The sulphhydric acid odour has entirely disappeared.

Such water may then be recycled. Of course this operation involves some cost which yields no return, but the fight against pollution is absolutely necessary, and the recovery of fatty matter, which helps to lower costs, should not be discounted.

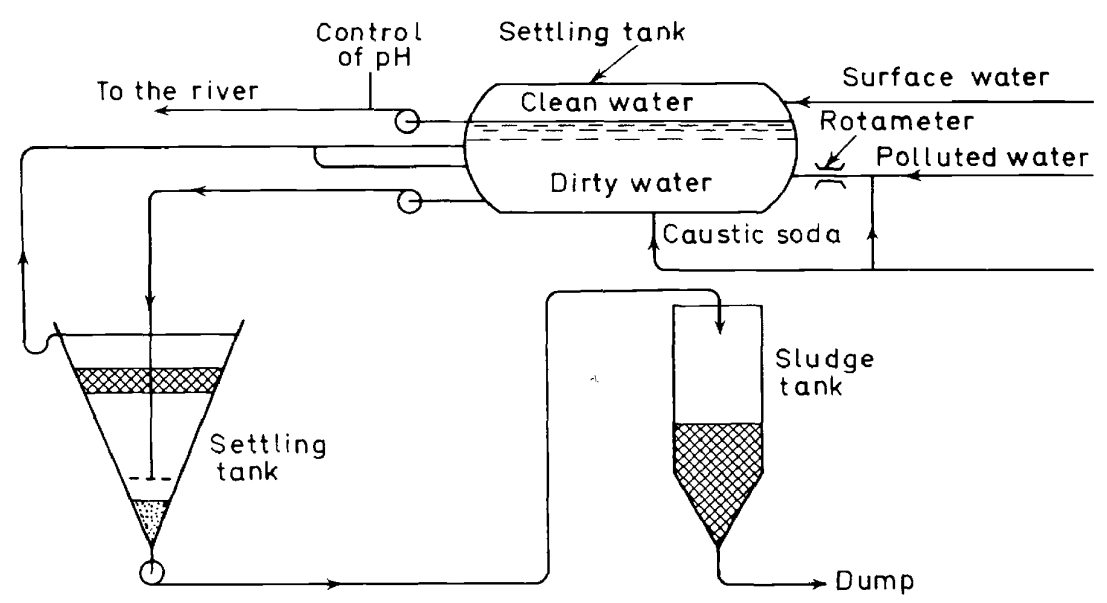

Figure 3. Chemical treatment of polluted water.

\section{MARGARINE INDUSTRY}

The margarine industry only uses substances that have already been refined. It is therefore rightly considered as a clean industry and is not included on the list of unhygienic or nuisance industries.

Two categories of water are used. One is a direct ingredient for margarine (fermentation of the milk, and preparation of the additives solution as emulsified salt solution etc). This water is chemically and bacteriologically pure. The other is used for cleaning and thorough rinsing of the equipment, the premises and the machines. It may show a high BOD which necessitates the twofold operation of clarification and biological purification.

The purifying process is the same as that used in the oil industry.

The technique of injecting aerated water into the base of the settling tray has been most satisfactory. Here is a typical example. On entering the apparatus from an ordinary settling tank, the water contains about $300 \mathrm{ppm}$ fatty matter. At the exit the average rate was $50 \mathrm{ppm}$ which corresponds roughly to a purification rate of about 85 per cent, and this percentage is extremely constant. 
In the margarine industry $5 \mathrm{~g}$ of matter in suspension and $50 \mathrm{~g}$ of oxidizable matter, per kg of margarine produced is tolerated in France, in waste waters.

\section{ANIMAL FATS INDUSTRY}

More rational methods for obtaining animal fats must first be sought before the means for purifying polluted waters resulting from this industry.

Indeed, it was not so long ago that the gathering of these crude fats (leaf fats) was carried out in very poor conditions of hygiene in the slaughter houses and at the butchers to say nothing of their collection, transportation and preservation.

These methods resulted in considerable and rapid decomposition due to the presence of 'lipases' and other enzymes, and thus cleaning and treatment of even more water was required as it was even more polluted.

The first condition for optimum solution of the pollution problem in this industry is to stop the enzymatic action as rapidly as possible either by cold or by heat and to process the crude fats as quickly as possible.

For this, it would be necessary to do away with private enterprises where the tallow is never removed nor preserved in acceptable conditions and where the collecting cannot be done often enough, due to the small quantity produced.

Likewise, new or renovated slaughter houses must set aside suitable areas for the collection of tallow and by-products under favourable conditions.

Immediately after removal tallow must be placed in tanks of cold running water, where after a sufficiently long soaking, it is cooled and freed from blood and dirt.

The drying which follows must also be very quick and storage before processing, very short.

There is much improvement to be made in this field.

During processing, water is used at several different stages: washing of the crude raw material, washing before cooking (preceded by a dry smelting process); smelting in a wet environment (wet smelting) which necessitates settling later; waste water if there is further refining; washing and the rinsing of the equipment, premises and delivery trucks.

\section{Purification of the waste water}

The treatment of waste water in this industry, is similar to that in the oil and fats industries.

These waters appear in emulsion form. They contain finely divided fat particles as well as proteins and other substances in solution, easily broken down by hydrolysis or biological treatment.

Certainly, the water from some rendering houses is so clean that it may be discharged directly after simple dilution with cold water. This cooling dilution also presents the advantage of limiting evaporation with its accompanying odours. This is the case, for example, for water from lard which arrives at the rendering house perfectly fresh. However, this is rare and the case presenting a real nuisance is much more frequent.

Attempts have been made to pass these waters through sand or other types of continuous filters, but this presents clogging problems, besides the fact that the treatment is insufficient. 


\section{R. FRANCOIS}

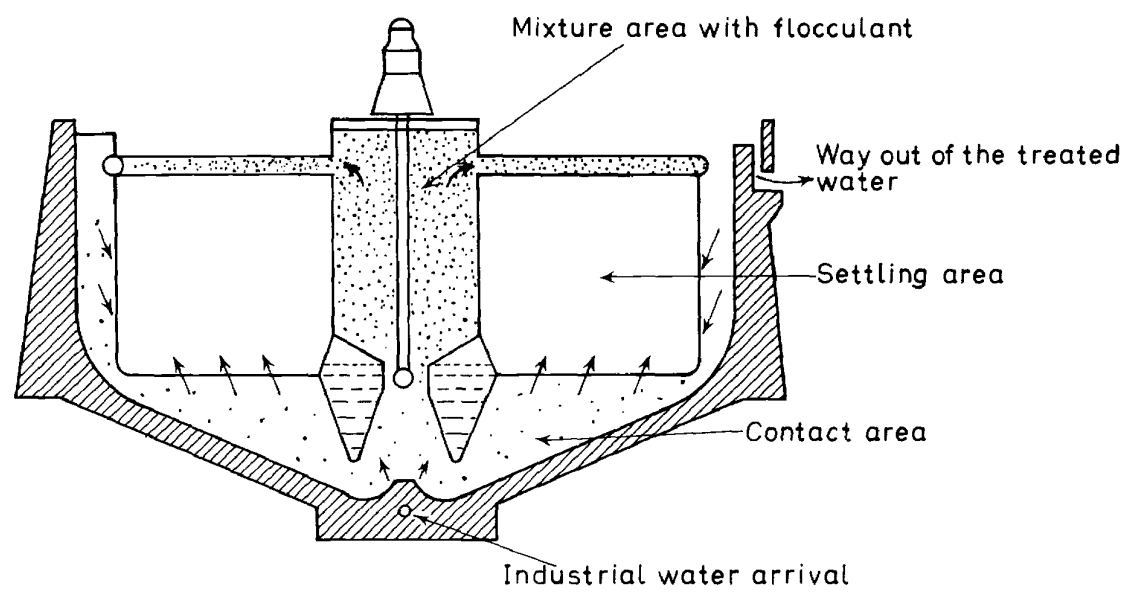

Figure 4. Wabag-type settler.

Purification techniques include two stages: settling and precipitation.

If the settling presents no special problem, the precipitation is a little different in this branch, due to the high protein content.

A metallic hydrate in gelatinous form is precipitated in the water after it has been freed from the biggest particles and thus, the rest of the suspended matter is carried down.

The process consists of bringing the water to an optimum $\mathrm{pH}$, for example, 8 , by adding a lime wash or by running it over a 'magnesium bed'. Then a flocculent solution is stirred in such as aluminium sulphate, ferric sulphate of ferric chloride. The best of these is aluminium sulphate.

After reaction and resting the settling is carried out and the solid residues are sent to the rubbish dump; they contain about five per cent of the water treated. As to the rest of the water, it may be pure enough to be sent to the sewer with or without dilution. If not, it undergoes aerobic fermentation before evacuation.

Other continuous process have been carried out during which the water and flocculating agent are mixed automatically and continuously and are brought to a certain level in the tank. The purified water flows off and the muds fall into a circumferential collector from which they are extracted.

During the flow into the different tanks, gases and vapours are given off which must, of course, be captured and destroyed.

Among the processes based on these principles, here are the results of one, in an industrial enterprise:

\begin{tabular}{lcc}
\multicolumn{3}{c}{ Analysis of waste water } \\
\hline & $\begin{array}{c}\text { Proportion in } \mathrm{mg} / \mathrm{l} \\
\text { After treatment }\end{array}$ \\
\hline Nitrogen & 1.065 & 134 \\
BOD & 21.000 & 1.200 \\
Fatty matters & 15.200 & 244 \\
Dry matters & 28.740 & 7.540 \\
\hline
\end{tabular}


The introduction of antiseptic products into the water should be avoided as they may stop or slow down the biological decomposition which is the basic principle of any purification process.

However, this consideration creates another problem, that of choosing products for the sterilization, disinfection and disinfestation of the premises.

Therefore, the animal fats industry, demands the organization and maintenance of perfect conditions of hygiene at every step of the processing and in the upkeep of the equipment.

\section{CONCLUSIONS}

What is the position of the State, and the attitude of the manufacturers, as to the consumption of this raw material, water, the sources of which are limited and in a constant state of degradation?

In France, water control is organised in each of the regions by committees called 'Comites des Bassins' comprised of representatives from the State, the local communities, and the users (farmers, manufacturers, fishermen).

These committees are entrusted with:

Maintaining the balance between resources and needs.

Fixing standards.

Helping to protect inhabitants against floods.

Deciding on levies which are of two sorts: pollution levies related to the harm resulting from pollution of the environment, caused by those who run off waste water into the rivers and streams; levies to pay for the operating of the purification plants to which the discards are transported.

All these measures, however logical and necessary do not solve the water consumption problem. Among the manufacturers, two attitudes appear: willingness to pay levies; the desire to carry out a water control programme not only to satisfy present purification needs, but also to preserve the supply of this increasingly precious raw material, an eventual shortage of which would have such serious consequences. This is the attitude which we must all approve and have. 